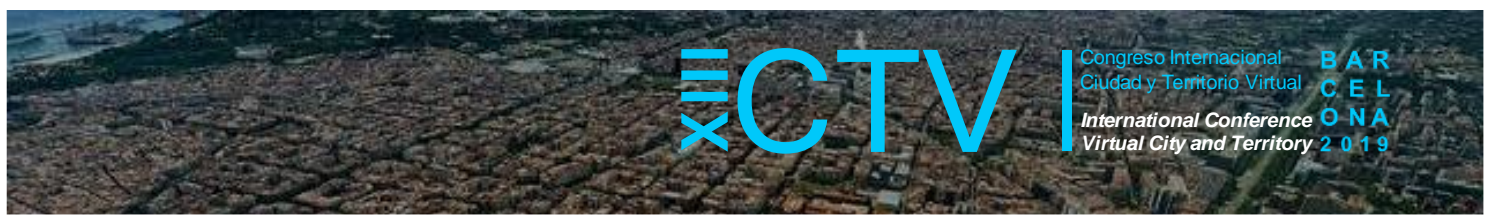

\title{
LA TRANSFORMACIÓN DEL SUELO VACANTE INDUSTRIAL COMO PRINCIPIO PARA LA COHESIÓN Y REGENERACIÓN DE LOS MUNICIPIOS DEL SUR DE MADRID
}

\author{
Ajuriaguerra Escudero, Miguel Ángel ${ }^{1 *}$; López Parejo, Alejandro ${ }^{2}$ y Areco Iglesias, Ezequiel ${ }^{3}$
}

Remisión inicial: 2019-07-16; Remisión definitiva: 2019-09-30; Publicación: 2019-12-21

Citación: Ajuriaguerra Escudero, M. Á. et al. (2019). La transformación del suelo vacante industrial como principio para la cohesión y regeneración de los municipios del sur de Madrid. XIII CTV 2019 Proceedings: XIII International Conference on Virtual City and Territory: "Challenges and paradigms of the contemporary city": UPC, Barcelona, October 2-4, 2019. Barcelona: CPSV, 2019, p. 8485. E-ISSN 2604-6512. DOI http://dx.doi.org/10.5821/ctv.8485

\section{Resumen}

Madrid, como tantas ciudades en el mundo, sufre una progresiva "turistificación" y gentrificación (Domínguez y Leal, 2008). Este proceso está transformando notablemente las características sociológicas de los entramados urbanos vecinales por nuevos espacios destinados a una población flotante, cuyos principales representantes son los turistas y los residentes temporales. Así, las actividades comerciales, sociales y culturales, tienden a fomentar la homogenización del espacio público en favor del consumidor de escala. Este proceso excluye progresivamente a la población local, la cual no puede hacer frente al incremento del coste del nivel de vida ni al progresivo deterioro y sustitución del entramado socioeconómico tradicional. La gentrificación lleva a su vez asociada un desplazamiento de la población a entornos más accesibles económicamente, localizadas principalmente en las periferias metropolitanas, en un claro proceso de "centrifugación social" (de Santiago Rodríguez 2007). No obstante, en las grandes ciudades y debido a la presión inmobiliaria, estas zonas mantienen unos precios de mercado muy superiores al poder adquisitivo medio. Esta circunstancia dificulta tanto el acceso a la vivienda como la implicación social en la mejora urbana.

En el caso de Madrid, y concretamente en el Distrito de Villaverde, este fenómeno se evidencia en unas rentabilidades de inversión inmobiliarias elevadas que, sin embargo, no se materializan ni en una mejora urbana ni en el aumento de la calidad de vida de los propietarios tradicionales de vivienda y comercio (Domínguez y Leal, 2008). De este modo, la presión inmobiliaria, sumada al progresivo envejecimiento de la población y el desmantelamiento de la industria del cinturón sureste de la capital favorece la degradación de estas áreas. Frente a ello, se plantea la necesidad de implantar distintas actuaciones efectivas que doten y regeneren de nuevo el entramado social, revirtiendo los crecientes niveles de exclusión.

Así, a lo largo del último año, se han analizado los agentes y grupos de interés más representativos del distrito de Villaverde (Madrid) y de sus municipios colindantes (Leganés y Getafe) con el objetivo de desarrollar una estrategia que permita la inclusión de nueva población, de perfil joven, compatible y complementaria a los entramados sociales tradicionales. De esta forma, el artículo expone mediante un análisis cuantitativo y cualitativo las alternativas urbanas posibles ante la demanda social. Y, especialmente con respecto a los escenarios de consenso con el fin de promover propuestas realistas de reutilización de las antiguas parcelas industriales vacantes de la zona. La metodología empleada en base a los costes de la vivienda y alquiler, ha permitido plantear una propuesta de actuación estratégica de regeneración urbana en fases respetando tanto las demandas sociales como los usos predominantes del suelo.

Para finalizar, se presentan las propuestas de estrategia de regeneración urbana sobre las parcelas industriales vacantes que mayor grado de aceptación ha obtenido entre los agentes y grupos de interés. De forma que se fomente la introducción de un nuevo uso y perfil vecinal para mejorar la cohesión social y urbana del sur de Madrid.

\footnotetext{
1 Doctor arquitecto por la Universidad Politécnica de Madrid y profesor visitante en la Universidad Rey Juan Carlos e Investigador principal del Grupo de Investigación del proyecto Madrid Borde Sur, https://orcid.org/0000-0001-86184194; ${ }^{2}$ Coordinador del proyecto Madrid Borde Sur y alumno del Doble Grado en Fundamentos de la Arquitectura y Diseño en la Universidad Rey Juan Carlos, https://orcid.org/0000-0001-5218-4831; ${ }^{3}$ Graduado en Fundamentos de la arquitectura por la Universidad Rey Juan Carlos y administrador del colectivo Madrid Borde Sur. * Correo de contacto: miguelangel.ajuriaguerra@urjc.es
} 


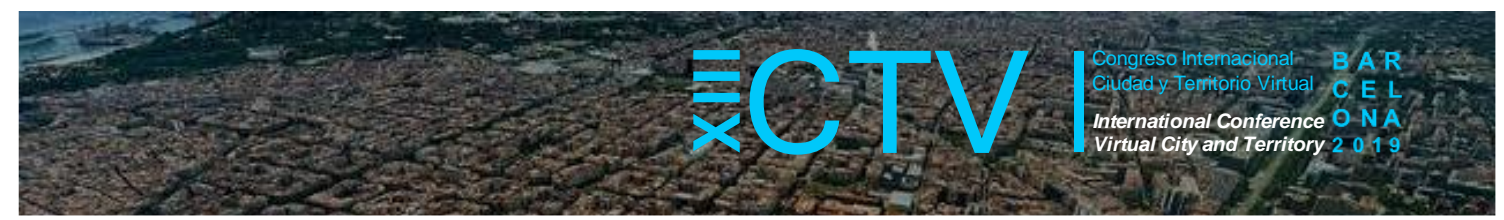

\section{Abstract}

Madrid, like many cities in the world, is undergoing a progressive "turistization" and gentrification (Dominguez \& Leal, 2008). This process is notably transforming the sociological characteristics of the urban spaces by new ones destined for a floating population, whose main representatives are tourists and temporary residents. Thus, commercial, social and cultural activities tend to promote the homogenization of public space in favor of the consumer of scale. This process progressively excludes the local population which cannot cope with the increase in the cost of living or the progressive deterioration and replacement of the traditional socio-economic framework. Gentrification in turn leads to a displacement of the local population to environments that are more economically accessible, mainly located in the metropolitan peripheries, in a clear process of "social centrifugation" (Santiago Rodríguez, 2007). However, in large cities, and due to real estate pressure, these areas maintain market prices that are much higher than the average purchasing power. This circumstance hinders both access to housing and social involvement in a process of urban improvement.

In the case of Madrid, and specifically in the District of Villaverde, this phenomenon is evidenced in high returns on real estate investment that do not materialize, however, either in an improvement of the urban space or in the increase in the quality of life of the local owners of traditional housing and local commerce (Dominguez \& Leal 2008). In this way, the real estate pressure, added to the progressive aging of the population and the dismantling of the belt industry located in the southeast of the capital favors the degradation of these areas. In view of this, the need to implement different effective actions that endow and regenerate the social network is raised, in order to reverse the increasing levels of exclusion. Thus, over the last year, the most representative agents and interest groups of the district of Villaverde (Madrid) and its neighboring municipalities (Leganés and Getafe) have been analyzed in order to develop a strategy that allows the inclusion of new population, young profile, compatible and complementary to traditional social networks. In this way, the article exposes through a quantitative and qualitative analysis the possible urban alternatives to social demand. And, especially with regard to the consensus scenarios in order to promote proposals that are realistic for the reuse of the old vacant industrial plots in these areas. The methodology used based on the costs of housing and rent has allowed us to propose a strategic action proposal for urban regeneration in phases, respecting both social demands and predominant land uses.

Finally, the proposals for an urban regeneration strategy on vacant industrial plots that have obtained greater acceptance among agents and interest groups are presented. So that the introduction of a new use and neighborhood profile is encouraged to improve the social and urban cohesion of southern Madrid.

Palabras Clave: Gentrificación; Villaverde; Madrid; Estrategia, Inmobiliaria

Key words: Gentrification; Villaverde; Madrid; Planification; Real Estate

\section{El contexto general del entramado socioeconómico de Villaverde}

La situación económica actual en la Comunidad de Madrid se caracteriza por una relevante captación de inversiones internacionales (Ministerio de Industria 2019) con un creciente interés hacia la inversión inmobiliaria por su fiabilidad y retornos de inversión (Bellod Redondo 2007). Así, tras la última crisis económica (2008-2012), se ha iniciado una serie de dinámicas urbanas relacionadas con la "economía colaborativa" (Alfonso Sánchez 2017). De esta forma, estos nuevos actores empresariales, entre otros, han contribuido a acelerar algunos procesos de gentrificación (Hiernaux y González 2014).

\section{Figura 1. Flujos de inversión en el ámbito inmobiliario en la CAM procedentes de países OCDE}

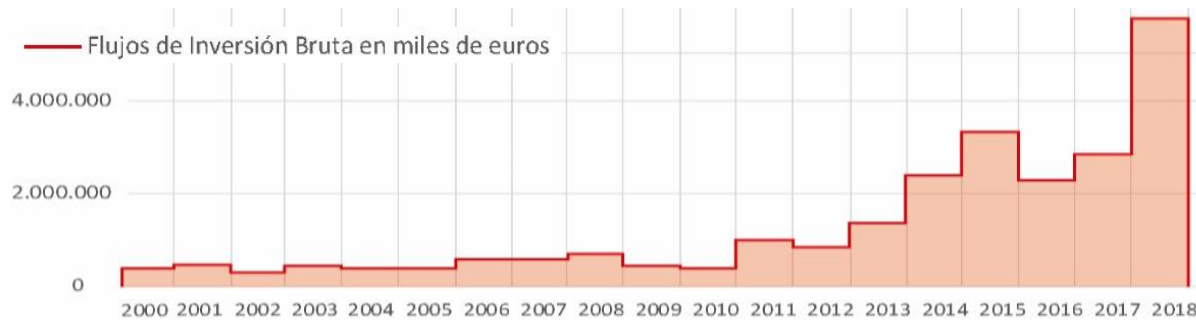

Fuente: Elaboración propia con datos del Ministerio de Industria (2019). 


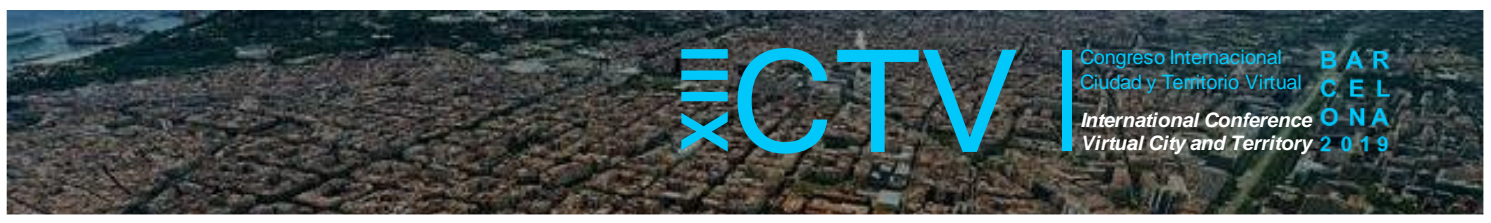

De manera concreta en el caso de Madrid, el progreso de este fenómeno no ha sido similar en todos los distritos de la capital, existiendo un proceso evidente en el impulso de la gentrificación en la "almendra central", con especial afección en los barrios de Chueca o Malasaña (García Pérez 2014), los cuales han experimentado este fenómeno en un proceso escalonado y lineal (García Pérez 2014). Por otro lado, en el conjunto de la ciudad de Madrid la inversión inmobiliaria se ha visto incrementada en la última década como consecuencia de la llegada de nuevos inquilinos e inversores de forma rápida tras el fin de la crisis económica de 2008 (Ministerio de Industria 2019).

En este sentido, la evolución del precio de la vivienda refleja el incremento de los precios de venta que se han experimentado en los barrios tradicionalmente céntricos. De esta forma, en los distritos Centro-Arganzuela-Tetuán la media del incremento del precio de la vivienda entre 20002009 ha sido aproximadamente de un 196,11\%. En este periodo, en los barrios periféricos de Villaverde-Carabanchel-Puente de Vallecas el incremento experimentado es de una media de 214,81\% (Muñoz Carrera 2011).

Por ello, si se analiza la evolución del precio de venta de vivienda entre los distritos CentroPuente de Vallecas-Villaverde se aprecia cómo el incremento más notable se produce durante la "burbuja inmobiliaria". Este fenómeno se debió, en parte, al fácil acceso a préstamos hipotecarios $y$ al nivel de endeudamiento de las familias (Bellod Redondo 2007).

Figura 2. Mapa de distritos de Madrid, almendra central y Villaverde

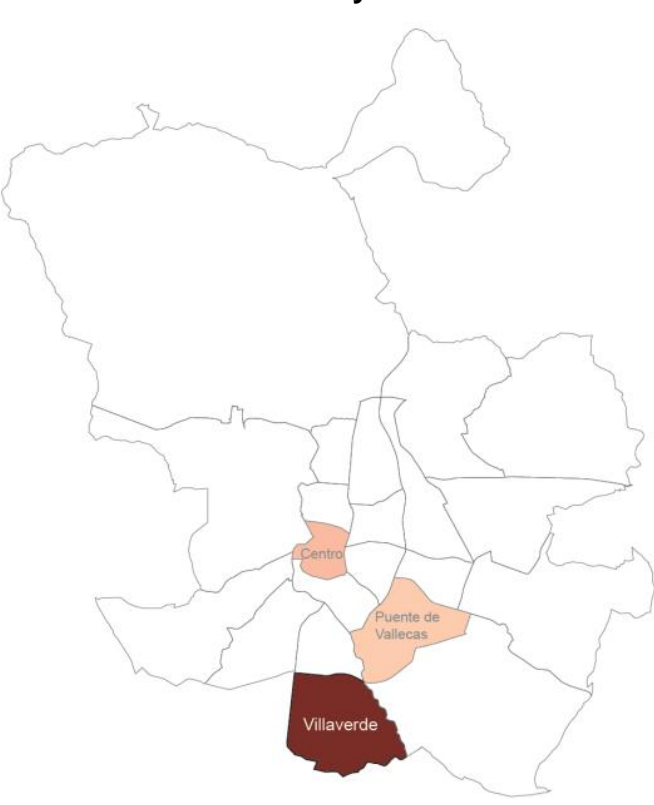

Fuente: elaboración propia.

Figuras 3 y 4. Gráfica comparativa de la evolución del precio de la vivienda de segunda mano y alquiler en los distritos Centro frente a Puente de Vallecas y Villaverde

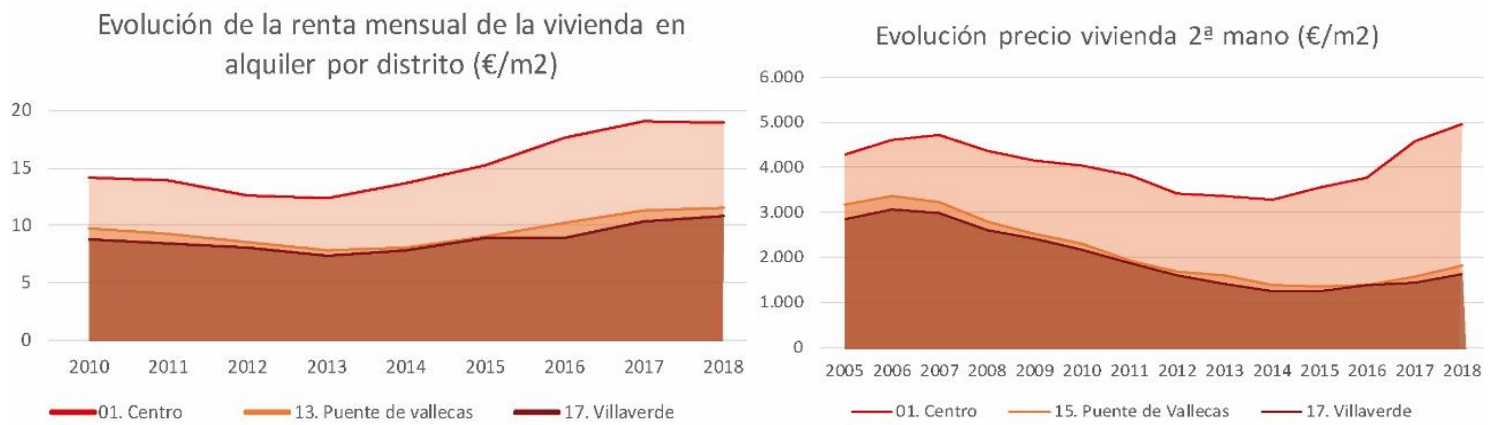

Fuente: elaboración propia a partir de datos del (Ayuntamiento de Madrid 2018).

En el periodo actual, especialmente a partir de 2014, se evidencia un ascenso paulatino en los precios -tanto alquiler como venta- como consecuencia de la demanda de vivienda e inversión inmobiliaria nacional e internacional (Ministerio de Industria 2019). 


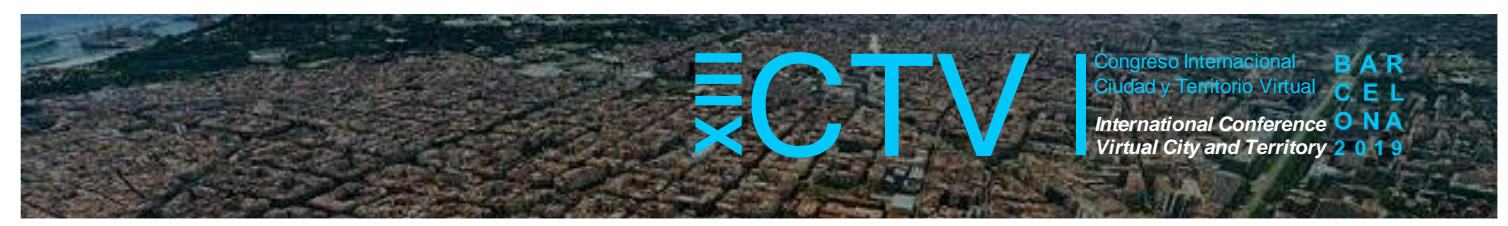

Con respecto al aspecto social, en la ciudad de Madrid se aprecia una diferencia socioeconómica significativa entre los distritos del sur y los del norte (Ayuntamiento de Madrid y UC3M 2018). De esta forma, uno de los distritos con mayor problemática social es el distrito de Villaverde (Hernández Aja et al. 2018). Cuyo crecimiento fue significativo durante el desarrollismo franquista (Fernández Gómez 2004). No obstante, la reconversión industrial sufrida en las últimas décadas ha afectado directamente a las características sociales del distrito por las prejubilaciones, altas tasas de desempleo y un progresivo abandono del suelo industrial, desmantelado y vacante en la actualidad (Ajuriaguerra et al. 2019).

Además, los datos de desempleo y paro se han mantenido entre los más elevados de municipio (Ayuntamiento de Madrid 2018). El distrito acoge un importante porcentaje de población inmigrante y de poca cualificación, algo que se evidencia en su $3,5 \%$ de profesionales de alta cualificación (Ayuntamiento de Madrid 2018). Esta realidad complejiza la situación socioeconómica del distrito, derivando en muchos casos hacia una mayor segregación social y el aumento de desigualdades (Ayuntamiento de Madrid y UC3M 2018).

Por ello, a pesar de los avances e inversiones de las últimas décadas, el distrito de Villaverde se mantiene en una situación de vulnerabilidad tal como recogen los estudios del propio consistorio (Ayuntamiento de Madrid y UC3M 2018). Todos los factores anteriormente expuestos se concretan en espacios urbanos segregados con rentas significativamente bajas (renta anual de $19.208 €$ ) en comparación con los distritos del entorno como ArganzuelaDelicias $(27.488 €)$, o municipios como Getafe $(25.646 €)$ y Leganés $(23.437 €)^{2}$. Esta realidad genera bolsas de marginalidad y de abandono en barrios como San Cristóbal o San Andrés (Ajuriaguerra et al. 2019). Frente a ello, las áreas del distrito con mejores dotaciones y conectividad, han comenzado a absorber trabajadores desplazados con mejores niveles de renta.

El conjunto de todos estos factores completan los procesos de gentrificación producidos en el centro de Madrid y en el distrito de Villaverde (Hiernaux y González 2014). Ya que, de acuerdo con las diversas teorías de gentrificación y su articulación urbana (García Pérez 2014; Hiernaux y González 2014; Parra 2014), su buena localización y características socioeconómicas hacen de Villaverde uno de los distritos más atractivos para tanto los especuladores como los nuevos perfiles socioeconómicos desplazados a las periferias de Madrid (Muñoz Carrera 2011).

\subsection{La problemática actual de insatisfacción ante la demanda de vivienda accesible.}

En el municipio de Madrid el acceso a la vivienda barata es complejo. Aunque, en general ésta se determina principalmente por las características de distancia, localización y niveles socioeconómicos al núcleo central. Por ello, es importante definir qué se entiende por acceso a la vivienda y por barata o accesible, tanto con respecto al precio de venta como de alquiler.

La opción más destacada para averiguar si una vivienda es accesible es mediante el índice Price Earnings Ratio, en adelante PER, junto con la comparativa del precio de venta o alquiler. No obstante, el PER es especialmente destinado a la inversión inmobiliaria. El Banco de

\footnotetext{
${ }^{2}$ Datos relativos a la renta media disponible. (Agencia Tributaria 2016)
} 


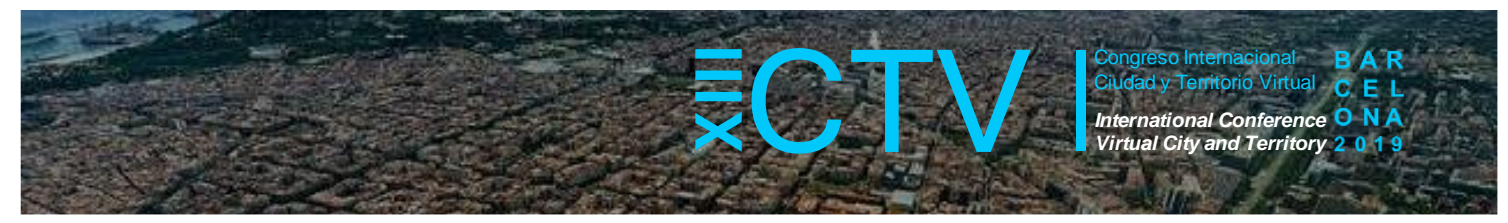

España también publica trimestralmente la rentabilidad bruta del alquiler (Banco de España 2019). De esta forma, se destaca que en el primer trimestre de 2019 la rentabilidad bruta del alquiler en España fue del 3,9\% por lo que el PER es de 25,6 años. Con este dato se puede calcular el precio de venta de una vivienda conociendo su alquiler y viceversa. No obstante, salvo conocedor del mercado es difícil determinar si el precio de una vivienda es accesible en compra o alquiler porque siempre depende de la comparación con otros inmuebles similares. Por ello, es importante considerar otras fórmulas para poder determinar si el acceso a una vivienda es accesible y asumible por un amplio margen de la población.

De entre las posibilidades para determinar el término barato con respecto al acceso a la vivienda se puede destacar el porcentaje de salario destinado a sufragar el coste mensual de una hipoteca o alquiler. En el caso de la Comunidad de Madrid, y siguiendo los datos de la Estadística Registral Inmobiliaria del Colegio de Registradores de la Propiedad, se puede destacar que el $42,75 \%$ de los ingresos se destinan a pagar el alquiler (Corbi 2019), solo superado por la Comunidad Autónoma de las Islas Baleares. El gasto medio anual en la Comunidad de Madrid por hogar se encuentra entre 34.016,49 y 13.708,50 € por persona (Instituto de Estadística, Comunidad de Madrid 2019). A su vez, se destaca que el Banco de España aconseja no destinar más del $35 \%$ de los ingresos al alquiler, una cifra alejada del $42,75 \%$ actual (Lantigua 2019).

Figura 5. \% de renta dedicada al alquiler e hipoteca en España y en CAM

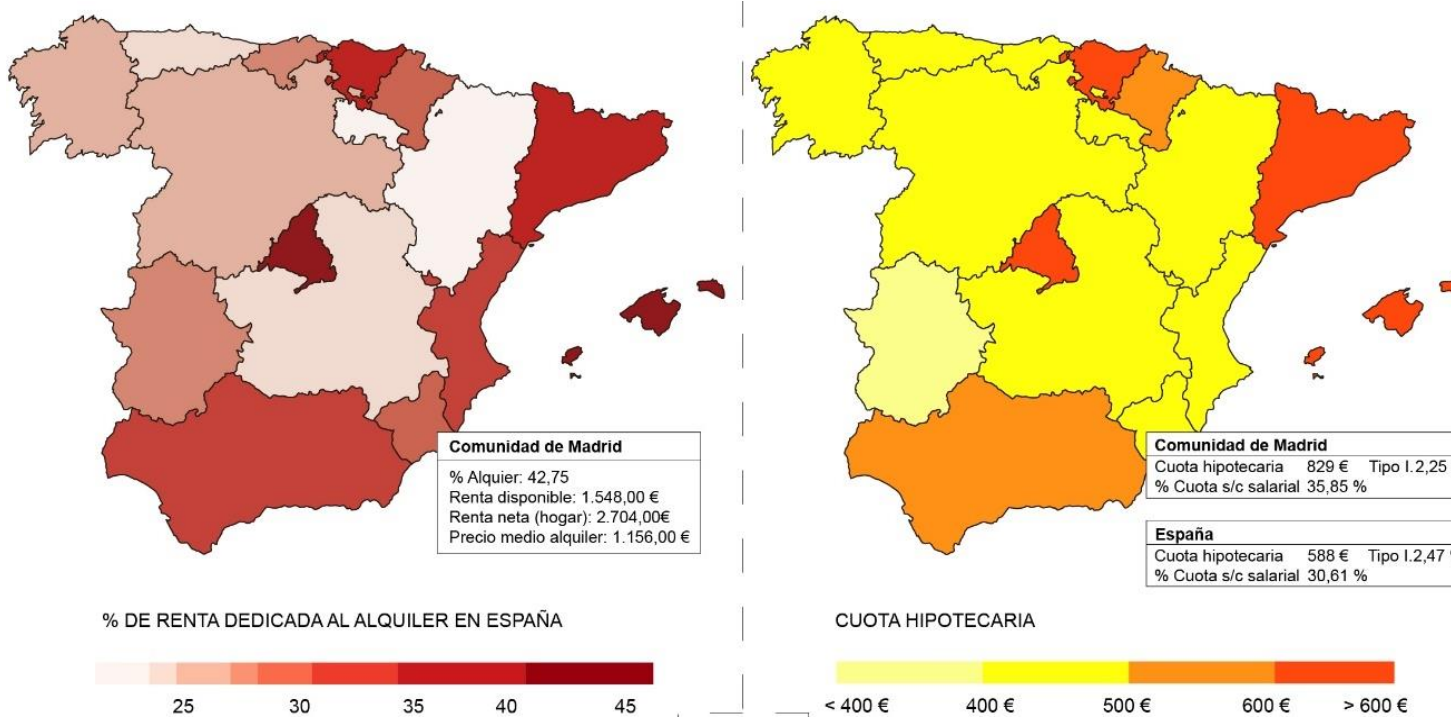

Fuente: elaboración propia a partir de gráficas de Miquel Corbi según fuentes del INE.

A su vez, es importante señalar que el gasto mensual hipotecario en la Comunidad de Madrid, aunque es menor que en alquiler, alcanza unas cotas medias de $829 €$. Las cuales suponen un $35,85 \%$ de los ingresos mensuales, siendo la cuota hipotecaria más alta de España (Instituto de Estadística, Comunidad de Madrid 2019). No obstante, este porcentaje resulta próximo al que el Banco de España estipula como el máximo recomendable para destinar al alquiler.

Esta situación pone en cuestión el término barato en la vivienda y deriva en otra nueva interpretación con respecto a los ingresos reales en la Comunidad de Madrid. Así, el salario medio bruto mensual de la Comunidad es de 2.191,7 €, y dependiendo de las circunstancias 


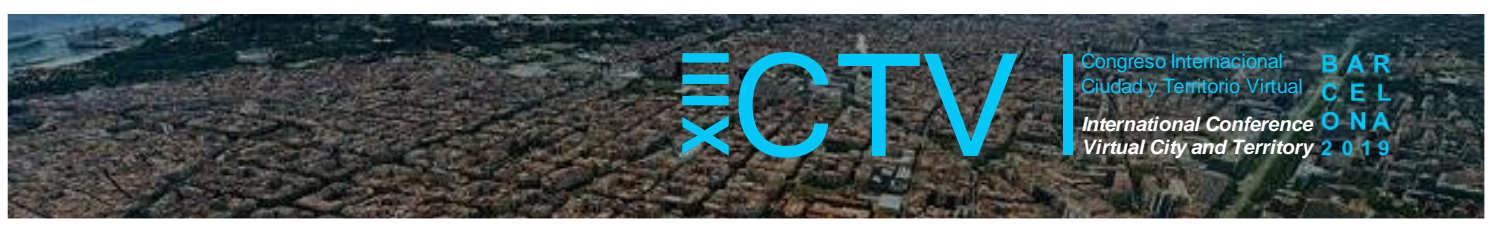

personales tras la aplicación de los impuestos pertinentes implica una renta media de en torno a $1.500 €$ mensuales (INE, 2017). No obstante, en la Comunidad de Madrid la realidad de ingresos varía notablemente entre municipios. $Y$, en el caso de Madrid dependiendo del distrito y barrio de residencia pueden existir diferencias de miles de euros anuales como ocurre en los distritos de Moncloa-Aravaca: 112.320,75 € frente a San Cristóbal: 19.587,09 $€$ (Ayuntamiento de Madrid, 2015). Esta diferenciación entre rentas familiares permite entender lo que puede suponer en términos económicos el acceso a una vivienda en distritos como el de Villaverde, con un nivel de renta significativamente menor. De este modo, en el caso de Madrid, la vivienda "barata" en términos comparativos no significa accesible económicamente. Por ello, si atendemos a las características de los ingresos en Villaverde, el término barato debe acercarse a una realidad de ingresos bajos que permitan a las familias, al menos, el alquiler o compra de viviendas. De este modo, si se atiende a la renta disponible en el distrito de Villaverde y concretamente en el barrio más desfavorable, San Cristóbal, cuya renta media es de 19.587,09 $€$ (Ayuntamiento de Madrid, 2015), se debe reconfigurar el término barato para dar así respuesta a la demanda de acceso a una vivienda.

\section{Figura 6. Niveles de renta por distritos censales}

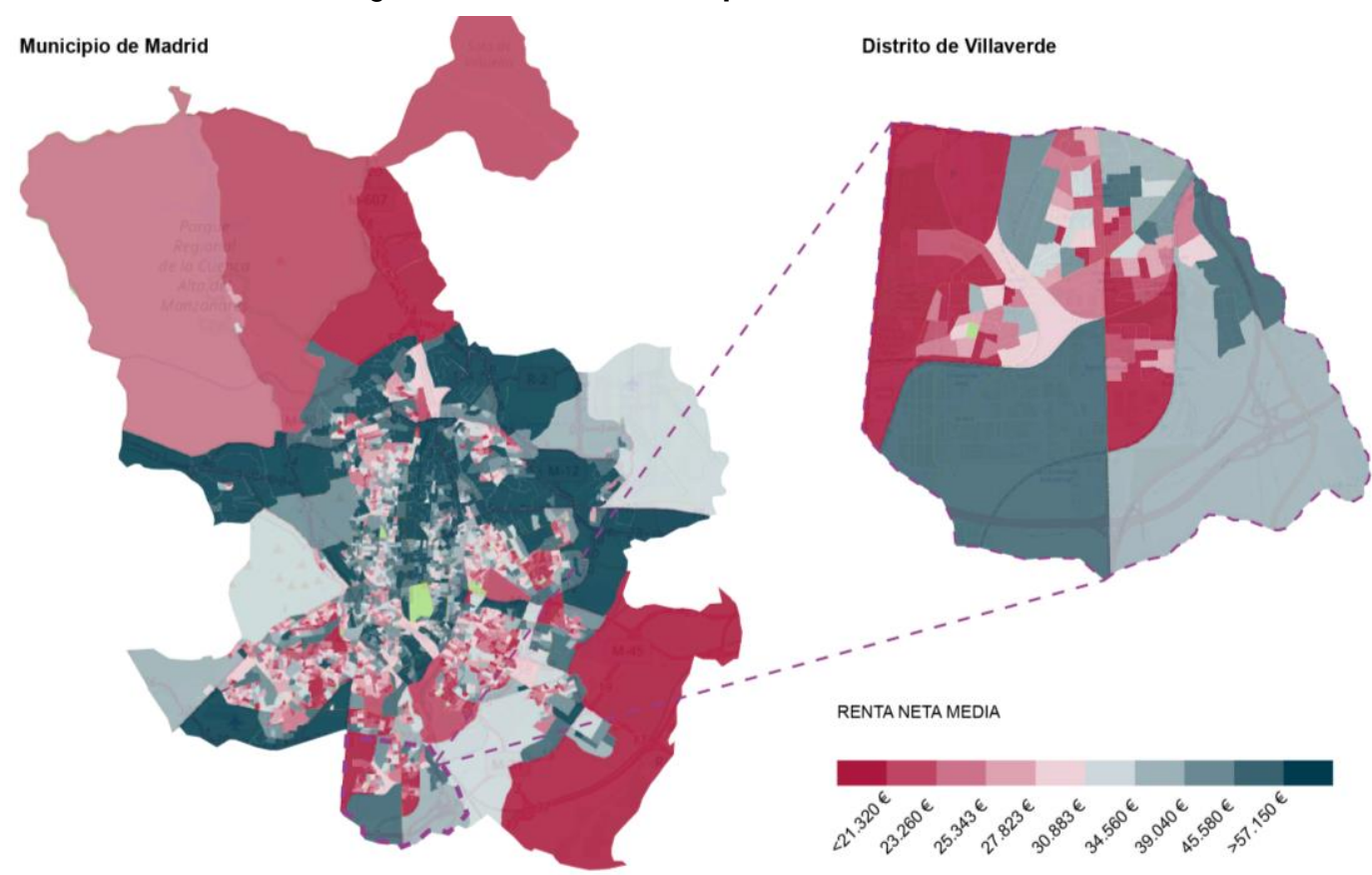

Fuente: El Confidencial y Ayuntamiento de Madrid.

Especialmente, si se atiende a que en dicho barrio se dispone de una superficie de suelo industrial vacante lo suficientemente grande para absorber la demanda de una vivienda "barata" no solo del distrito sino del resto de municipios colindantes, incluyendo a otros distritos de Madrid. De esta forma, atendiendo a las necesidades de la dimensión económica del barrio y del distrito, una aproximación al término barato para viviendas, y por consiguiente accesible, es objetivar los precios de venta y alquiler acorde al vigente salario mínimo de $900 €$ (Real Decreto 1462/2018). Por ello, si se siguen los consejos del Banco de España de no destinar más del $35 \%$ de los ingresos a los gastos hipotecarios, y extendiéndolo también al alquiler, se puede esclarecer la siguiente tabla de costes con respecto a los ingresos para hacer frente a los costes de un alquiler o hipoteca para el acceso a una vivienda. 


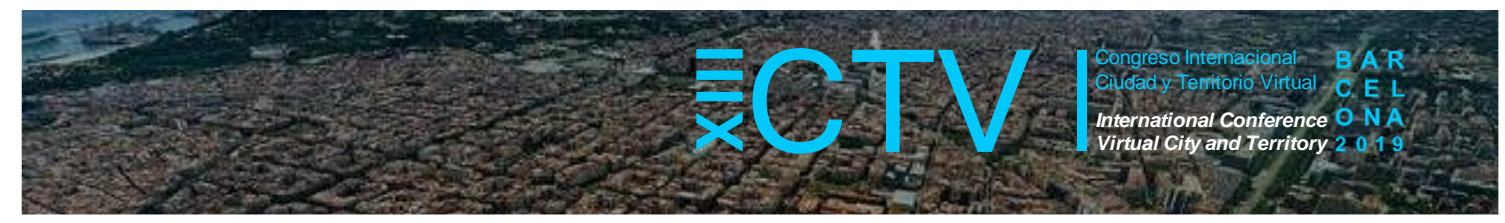

Tabla 1. Tabla de porcentaje real destinado a alquiler o compra de viviendas en Madrid según SMI

\begin{tabular}{|c|c|c|c|}
\hline $\begin{array}{c}N .{ }^{\circ} \text { de } \\
\text { miembros con } \\
\text { ingresos }\end{array}$ & $\begin{array}{c}\text { Base del RD } \\
1462 / 2018\end{array}$ & $\begin{array}{c}35 \% \text { Renta disponible } \\
\text { (Hipoteca o Alquiler) } \\
\text { /Mes }\end{array}$ & $\begin{array}{c}\text { PER Actual 25,6 } \\
\text { años }\end{array}$ \\
\hline 1 & 900 & $315 €$ & $96.768 €$ \\
\hline 2 & 1800 & $630 €$ & $193.536 €$ \\
\hline 3 & 2700 & $945 €$ & $290.304 €$ \\
\hline
\end{tabular}

Fuente: elaboración propia.

\section{Metodología de investigación, hallazgos y potencialidades}

En el contexto teórico descrito anteriormente, y tras analizar mediante una recopilación de muestras inmobiliarias de los portales más representativos (Idealista y Fotocasa) junto con el valor de venta de una vivienda por el portal del Banco Bilbao Vizcaya Argentaria (BBVA) Valora, se pone en relieve la situación actual de los precios del alquiler y venta de vivienda en Villaverde, y concretamente en el barrio de San Andrés.

Esta puesta en relieve de la situación socioeconómica del distrito de Villaverde se realiza en colaboración con los agentes sociales, políticos y económicos de la zona Sur de Madrid de forma que se puedan establecer potencialidades, mediante los hallazgos metodológicos, para la satisfacción de la demanda de vivienda accesible (Ajuriaguerra et al. 2019). Todo ello mediante la posible reconversión del suelo vacante de calificación industrial. De esta forma, la parcela de la anterior fábrica de producción de sistemas telefonía Standard-Villaverde, próxima al barrio de San Andrés y al Casco Histórico de Villaverde se manifiesta como la mejor opción para un cambio de uso y un desarrollo de vivienda social que satisfaga tanto las necesidades de vivienda como la revitalización del entramado urbano de los barrios colindantes.

En este sentido, y con el fin de poner en relieve aspectos manifestados durante la implantación metodológica, se destaca a continuación los aspectos más relevantes:

1. Emplazamiento: El área de estudio se sitúa en una zona estratégica de movilidad al situarse en un entorno de autovías de acceso junto con los servicios de transporte de autobuses, cercanías y metro. También es destacable la proximidad con los municipios del entorno. Si bien la movilidad actual es mejorable, especialmente con relación a los municipios colindantes, la red de transportes existente es más que suficiente para el desarrollo e implementación de propuestas que implique un aumento significativo del tránsito en las estaciones y líneas de transporte público cercanas.

2. Situación socioeconómica del área de estudio: Como se ha indicado con anterioridad, la situación socioeconómica del área se caracteriza por una serie de indicadores que la hacen especialmente vulnerable (Ayuntamiento de Madrid y UC3M 2018). Según los datos consultados, la realidad económica y de desempleo del distrito no ha evolucionado de manera favorable desde los años ochenta, algo que contrasta con la mayoría de los distritos de la capital (Ajuriaguerra et al., 2019). En este sentido cabe señalar la ausencia de planes y estrategias consensuadas por parte de las administraciones en el desarrollo y mejora de los distritos periféricos, muy especialmente de los del Sur y Sureste (Ajuriaguerra et al., 2019). A esto, se suma la bolsa de suelo vacante presente en el distrito de Villaverde fruto de las reconversiones industriales y que en la actualidad se mantienen vacante. 


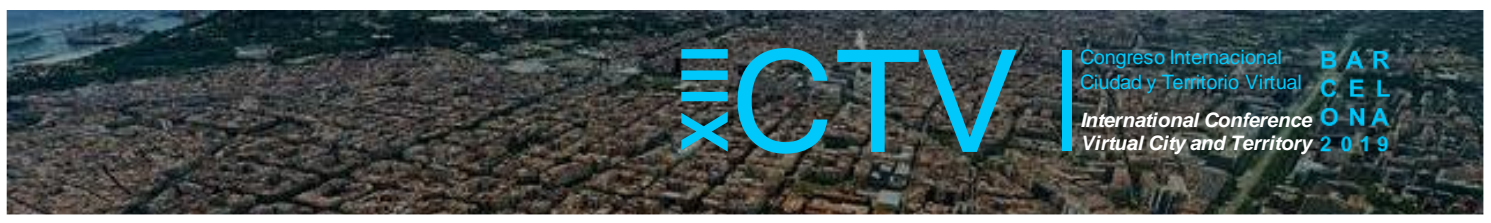

3. Contexto específico y ausencia de una estrategia: Como se viene identificando en análisis previos (Ajuriaguerra et al., 2019), el distrito de Villaverde sufre la ausencia de un planeamiento estratégico a medio y largo plazo más allá del PGOU 97. Además, tal y como se ha mencionado anteriormente, el precio de la vivienda ha aumentado significativamente más en áreas de la periferia Sur que en el Centro, un 18,7\% más en el periodo 2000-2009 (Muñoz Carrera 2011). De este modo, durante la toma de muestras de las viviendas en venta y en alquiler del Casco Histórico de Villaverde-Barrio de San Andrés, se ha recogido en el siguiente mapa las zonas de mayor precio con respecto a la distancia con la parcela industrial vacante objeto de reconversión.

Figura 7. Muestreo de viviendas en venta y alquiler en C. Histórico de Villaverde

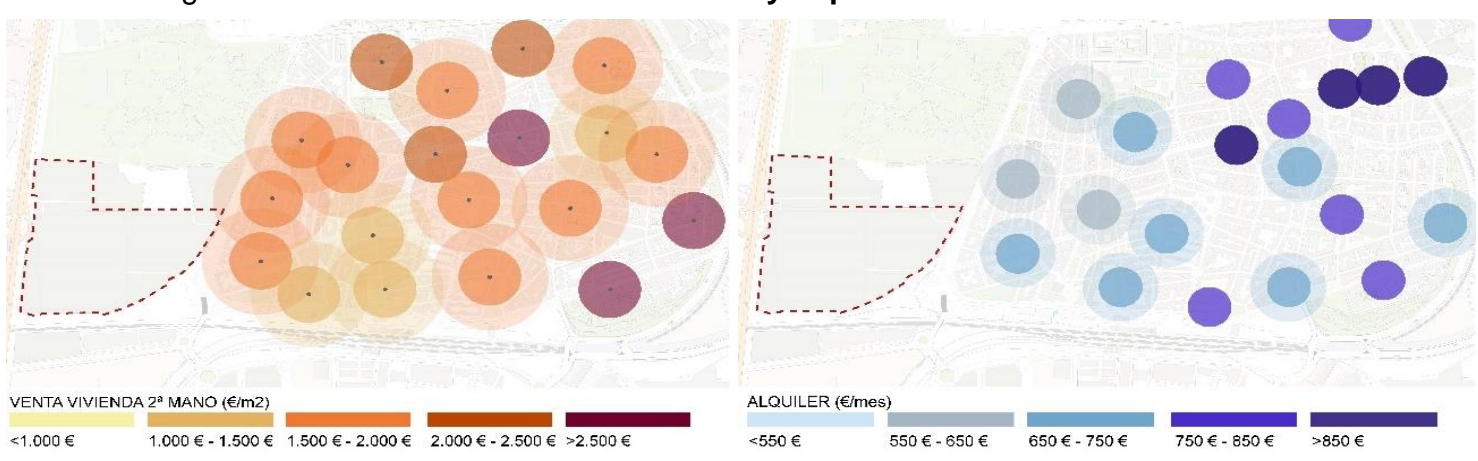

Fuente: elaboración propia a partir de datos de portales inmobiliarios (Idealista, BBVA y GoolZoom, 2019).

Como se aprecia en la figura 8, con muestras de alquiler y venta superpuestas, existe una mayor concentración de precios elevados en la zona noroeste. También se destaca una concentración de viviendas significativamente más asequibles en la zona suroeste.

Figura 8. Muestreo de viviendas en venta y alquiler en $\mathrm{C}$. Histórico de Villaverde.

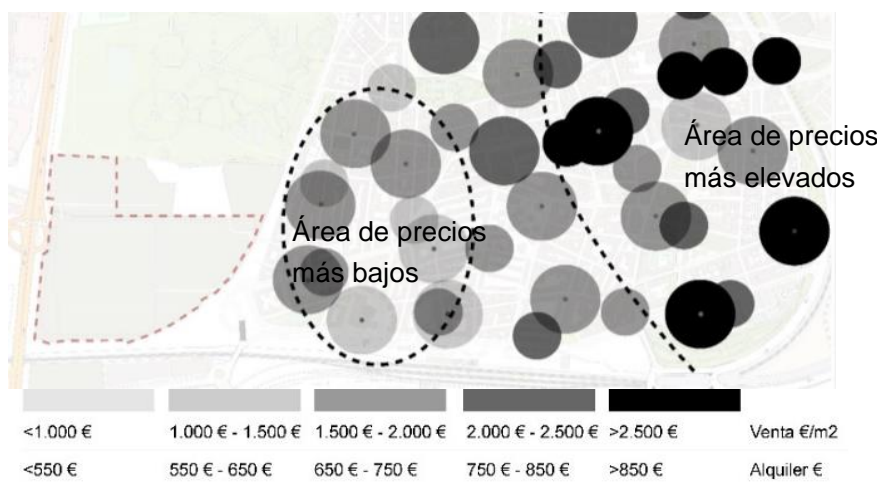

Fuente: elaboración propia a partir de datos de portales inmobiliarios (Idealista, BBVA y GoolZoom, 2019)

Con respecto a la ubicación y movilidad en medios de transporte público del área de estudio se destaca la existencia de dos estaciones de Cercanías. Concretamente, próxima a la parcela de Estándar, se encuentra la estación de Villaverde Alto, que sirve de intercambiador entre las líneas C4 y C5 de Cercanías y la línea 3 de Metro de Madrid.

De esta forma, y siguiendo las demandas vecinales del distrito, se proponen tres vías de desarrollo para la parcela de Standard. La cual, debido a su carácter vacante, ofrece una oportunidad para realizar actuaciones de mejora que a su vez revitalicen el entramado del 


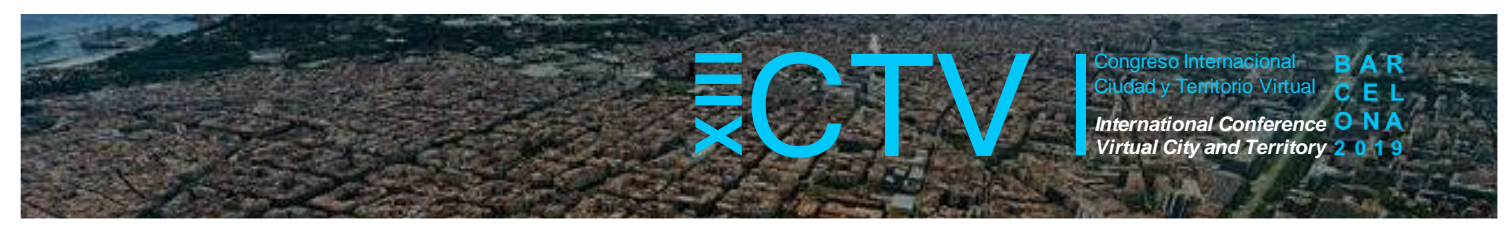

distrito no solo como respuesta a la inversión especulativa sino también como modo de consolidar los residentes tradicionales con los prospectivos. A continuación, se exponen las tres propuestas, diferenciadas según los usos:

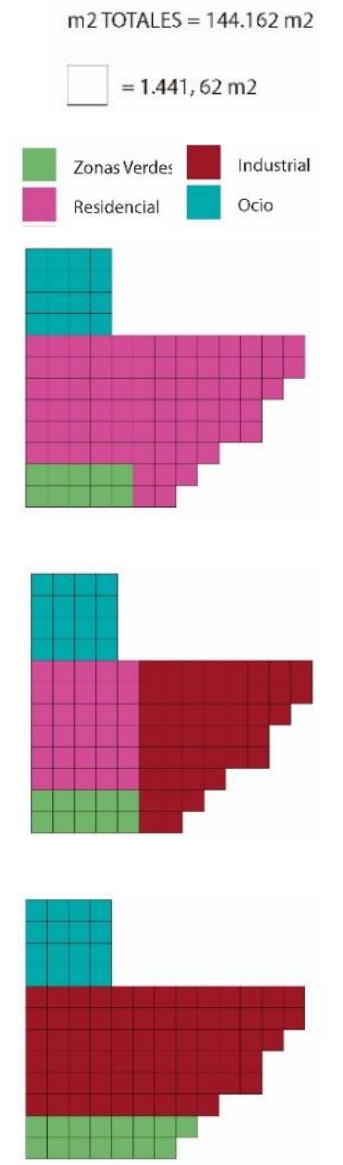

\section{PROPUESTA RESIDENCIAL}

Modificación de usos para el desarrollo de un campus residencial tanto para estudiantes de las universidades públicas del sur de Madrid como para los habitantes del barrio para fortalecer la identidad cultural, el espíritu comunitario y el rejuvenecimiento del área mediante una prospectiva de población joven. Esta propuesta residencial alberga otros usos y, atendiendo a las demandas sociales, se proponen implantar los siguientes espacios: residencia de estudiantes, residencia de mayores, áreas residenciales para personas en riesgo de, y en exclusión, zonas verdes conectadas con la red del Manzanares (Madrid Rio), zonas deportivas y de ocio, culturales y multiusos, que den servicio tanto al área residencial como al barrio.

\section{PROPUESTA RESIDENCIAL Y PRODUCTIVO}

Modificación parcial de usos de la parcela propuesta para el desarrollo de un área residencial abierta a la comunidad junto con un área productiva de industria ligera. Dentro del área residencial se proponen los mismos usos que en la propuesta anterior en menor escala y compatibles con un área industrial productiva en colaboración con el entramado de semilleros y programas de emprendimiento de Villaverde y de municipios del sur. En la cual se implantará también un huerto solar para el auto consumo y suministro eléctrico

\section{PROPUESTA PRODUCTIVA}

Mantenimiento de los usos industriales en la parcela mediante la introducción de nuevas áreas productivas mediante un huerto solar de alto rendimiento y zonas de industria ligera como la logística, la cual se quiere consolidar en Villaverde como el polo logístico sur de Madrid.

\subsection{Matriz de potencialidades en los usos propuestos}

Con relación al aprovechamiento de los servicios y ante las perspectivas de apoyo social, económico e institucional; previsible tras los talleres realizados en estudios previos para cada una de las propuestas. Se destaca que: con el objetivo de evidenciar qué usos tendrían una mayor viabilidad en la parcela de estudio se tienen en cuenta los siguientes factores de análisis, proporcionando una puntuación de $-1,0$ ó 1, en función de la ausencia o existencia de cada una de esas variables en las propuestas planteadas.

Finalmente se realiza un coeficiente de corrección que varía entre 0,5 (cuando es considerado negativo), 2,5 (si se considera positivo o neutro) y 5 (si se considera muy positivo), en función de la percepción de uso más o menos idóneo mostrado por los agentes consultados en cada caso (Ajuriaguerra et al., 2019). De esta forma, a continuación, se muestra la tabla 2 junto con los criterios objetivos de valoración identificados en cinco bloques principales: 


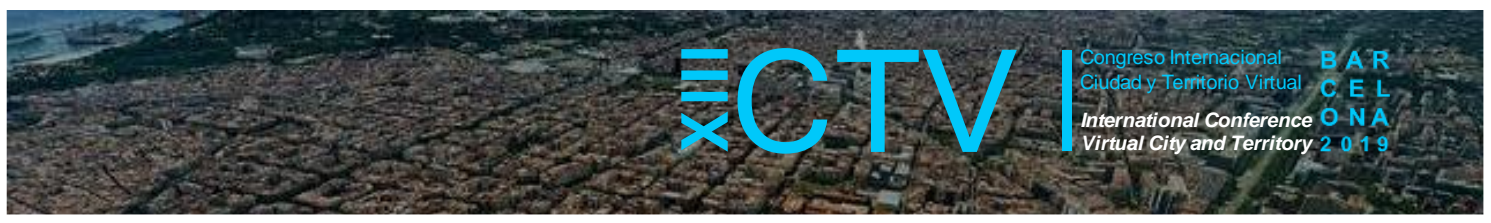

Tabla 2. Tabla de valoración de las propuestas puntuada según los criterios de valoración

\begin{tabular}{|c|c|c|c|c|c|c|}
\hline Usos planteados & \begin{tabular}{|l|} 
Industrial \\
(productivo)
\end{tabular} & Comercial & Residencial & \begin{tabular}{|l|} 
Residencial+ \\
Productivo
\end{tabular} & Criterios de valoración & \\
\hline \multirow{23}{*}{$\begin{array}{l}\text { Valoración de usos: en caso } \\
\text { afirmativo } 1 \text {, neutro } 0 \text { y negativo -1 }\end{array}$} & 1 & 1 & 1 & 1 & Conexión con transporte público & \\
\hline & 0 & 1 & 1 & 1 & Metro & \\
\hline & 0 & 1 & 1 & 1 & Renfe & \\
\hline & 1 & 1 & 1 & 1 & Bus & \\
\hline & 1 & 1 & 1 & 1 & Conexión con transporte privado & \\
\hline & 1 & 1 & 1 & 1 & Acceso directo desde via de gran capacidad & \\
\hline & 0 & -1 & 1 & 1 & Itinrarios ciclistas & \\
\hline & 0 & 0 & 1 & 1 & Mejora del entorno urbano & \multirow{4}{*}{ 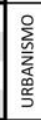 } \\
\hline & -1 & 0 & 1 & 1 & Integración con el tejido existente & \\
\hline & -1 & 0 & -1 & 1 & Implantación de dotaciones & \\
\hline & -1 & 0 & 1 & 1 & Implantación de áreas públicas & \\
\hline & 0 & 0 & 0 & 1 & Implementación y cierre de red verde (Madrid Rio-Plata Castañar) & \multirow{5}{*}{ 迹 } \\
\hline & -1 & 0 & 1 & 1 & Implementación y cierre de red ciclista & \\
\hline & 0 & 0 & 1 & 1 & Aumento de la masa vegetal y áreas arboladas & \\
\hline & 0 & 0 & 1 & 1 & Mejora del paisaje del área sur & \\
\hline & 0 & -1 & 1 & 1 & Aprovechamiento y fomento del uso de transporte público & \\
\hline & 1 & 1 & -1 & 1 & Reducción del desempleo en la zona & \\
\hline & 1 & 0 & 1 & 1 & Implementación de nuevo perfil vecinal & \\
\hline & 1 & 0 & 1 & 1 & Incremento de uso de infraestructuras de transporte público & \\
\hline & 0 & -1 & 1 & 1 & Disminución relativa de uso de infraestructuras de transporte privado & \\
\hline & 1 & -1 & -1 & 1 & Implementación de nuevas áreas productivas & \\
\hline & -1 & -1 & 1 & 1 & Implementación de área cultural & \\
\hline & -1 & 1 & 1 & 1 & Implementación de área de ocio & \\
\hline \multirow{4}{*}{$\begin{array}{l}\text { Valoración de viabilidad: } \\
\text { caso muy viable 2, viable 1, neutro } 0 \text {, } \\
\text { complejo - } 1\end{array}$} & 2 & 1 & 0 & -1 & Necesidad de menor inversión pública & \multirow{4}{*}{ 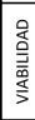 } \\
\hline & 2 & 1 & 0 & -1 & Necesidad de menor inversión privada & \\
\hline & 2 & 0 & -1 & -1 & Adecuación de la parcela al Plan General & \\
\hline & 2 & 0 & -1 & -1 & No es necesaria adaptación de la parcela para nuevos usos & \\
\hline \multirow{2}{*}{\multicolumn{5}{|c|}{\begin{tabular}{|l} 
Aplicación de coeficiente según \\
respaldo de agentes $(0,5 / 2,5 / 5)$
\end{tabular}}} & & \\
\hline & & & & & & \\
\hline Sociales & 50 & 2,5 & 7 & 95 & & \\
\hline Institucionales & 25 & 25 & 35 & 47,5 & & \\
\hline Empresariales & 25 & 25 & 35 & 9,5 & & \\
\hline TOTAL & 100 & 52,5 & 77 & 152 & & \\
\hline
\end{tabular}

Fuente: elaboración propia. Criterios de valoración: Movilidad, donde se analiza la capacidad de desarrollo de cada propuesta en función de su conexión con transporte público, así como transporte privado a través de acceso directo desde vías de gran capacidad o itinerarios ciclistas / Urbanismo: donde se analiza la capacidad de desarrollo de cada propuesta en función de su relación con el entorno urbano, posible integración con el tejido existente, implantación de dotaciones y servicios para el barrio y finalmente la creación de nuevos espacios públicos para la zona. Sostenibilidad: analizando la capacidad de inclusión de aspectos relacionados según cada una de las propuestas, con la implementación y cierre de un corredor verde entre Madrid Río y el parque forestal de Plata y Castañar, la implementación y cierre de una red ciclista de escala barrial con posibles conexiones con los municipios del entorno, el aumento de la masa arbórea del área, mejora del paisaje urbano del área sur así como el aprovechamiento y fomento del uso del transporte público previsible según cada propuesta. Repercusión: donde se analizan las posibles repercusiones de cada propuesta según su capacidad de reducción (estructural) ${ }^{3}$ de desempleo de la zona, la implementación de un nuevo perfil vecinal, incremento de uso de las infraestructuras de transporte existentes, tanto de transporte público como destinadas al transporte privado, la implementación de nuevas áreas productivas, de cultura y de ocio. Viabilidad: en este ámbito se analiza la viabilidad de cada una de las propuestas según la ordenación existente, la necesidad de inversión y la adecuación de la parcela, con un criterio algo distinto a los anteriores apartados (variando entre 2, 1, 0 y -1). Finalmente, según el respaldo de agentes se aplica un coeficiente de 0,5 en caso de respaldo negativo, 2,5 en caso de respaldo neutro y 5 en caso positivo.

De esta forma, se destaca que ante el problema del acceso a la vivienda y especialmente con relación a la necesidad de desarrollo de nuevas áreas residenciales que acojan tanto a la población desplazada de los distritos del centro como a la local con menores recursos económicos, el uso con un mayor interés para el área de estudio es el mixto residencial más productivo (logrando 152 puntos), seguido productivo (100), residencial (77) y finalmente el de ocio $(52,5)$. Esta valoración no es un dato concluyente, pues se basa en el análisis realizado en base a los criterios expuestos, el coste del acceso a la vivienda en compra o alquiler y a la participación de los grupos de interés más significativos del distrito de Villaverde y municipios ${ }^{3}$ No se tiene en cuenta la reducción puntual fruto del proceso de urbanización y edificación, que aplicaría en todos los
casos. 


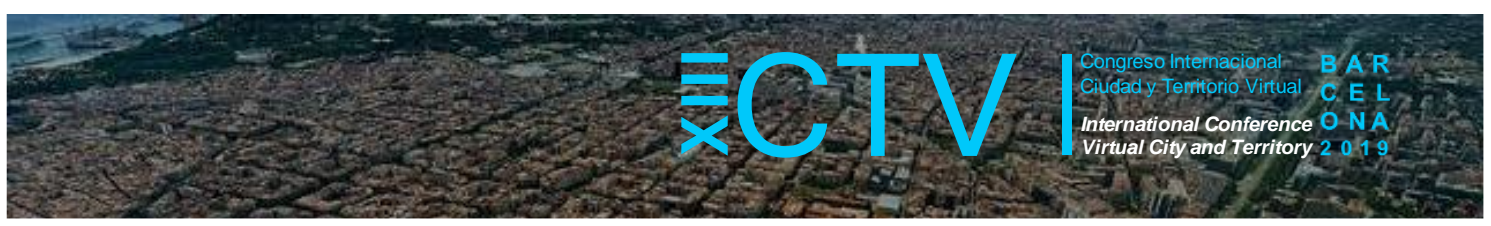

del sur. No obstante, estos aspectos permiten definir de forma más clara los usos que podrían implementarse en la parcela junto con una estrategia de implantación.

Como hallazgo principal, y satisfaciendo las posturas de participación, se destaca que la opción residencial y productiva, con usos mixtos para poder dar acceso a un mayor rango de ciudadanos y atraer a la población joven a un barrio degradado y envejecido que se debe potenciar en base a un diálogo mayor con los entes administrativos, incluso vinculando a las universidades públicas.

A continuación, en la figura 9, se muestra la movilidad con relación a los campus de las universidades públicas madrileñas. Los cuales se encuentran conectados a través de la red de transporte público de Metro y Cercanías. Así, se conoce el número total de campus públicos conectados que son siete, los cuales se encuentran conectados de forma directa (6 mediante la red de Cercanías y 1 a través de la red de Metro) y tres de forma indirecta con los servicios de autobuses y las líneas de metro del municipio de Madrid y de los municipios del sur (Madrid Metro Sur). Es importante destacar que, de esta forma, desde la estación de Villaverde Alto se presta servicio, en menos de 40 minutos, a un total de siete campus de cuatro Universidades públicas distintas.

Figura 9. Mapa de las líneas de Cercanías y Metro existentes en el entorno del área de propuesta, con relación a la estación de Villaverde Alto, y campus de Universidades públicas conectadas

Fuente: Elaboración propia.

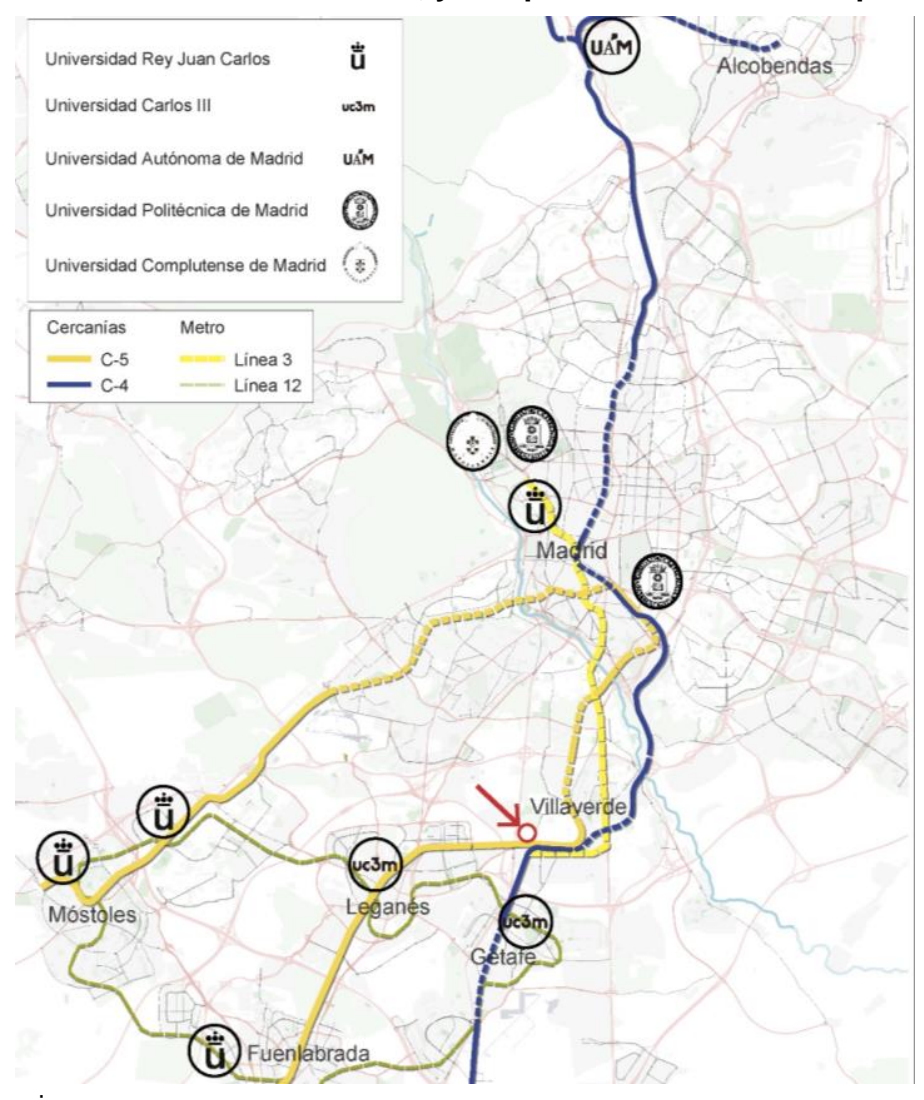

De este modo, se puede realizan una serie de consideraciones que tienen en cuenta los aspectos expuestos de los que se destacan: 


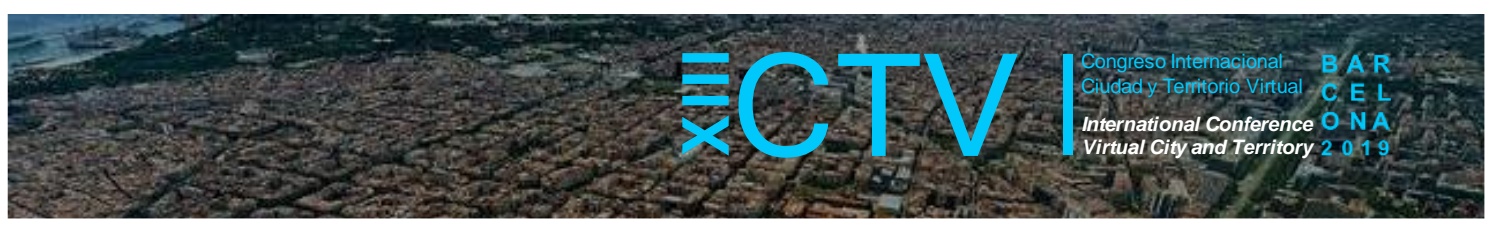

- El desarrollo de la parcela vacante mitiga los problemas de acceso a la vivienda, tanto en compra como en alquiler. Y, a su vez, el desarrollo de la parcela tiene un impacto positivo con respecto al resto del entorno urbano, introduciendo usos productivos adaptados a la realidad "industrial" actual.

- Las conexiones de transporte público y privado existentes en el área de estudio, así como las comunicaciones con distintos campus universitarios, optimizarían las opciones de movilidad mediante sistemas complementarios como vías ciclistas, corredores verdes y áreas peatonales.

- El acogimiento en la parcela de un área residencial universitaria y de jóvenes emancipados supone una mejora con respecto al rejuvenecimiento del barrio y potencia el desarrollo de nuevos servicios y comercios complementarios a los ya tradicionales.

Conforme a estos indicadores $\mathrm{y}$, atendiendo a la demanda de vivienda accesible en Villaverde, se plantea un desarrollo en fases piloto para poder desarrollar y ocupar progresivamente los suelos vacantes del distrito con el fin de reactivar las actividades económicas, productivas y dar solución al acceso a la vivienda para los grupos más desfavorecidos. Según el consenso entre agentes son los jóvenes universitarios o, recién emancipados, junto con grupos de la tercera edad que disponen de menos recursos económicos. (Ajuriaguerra et al., 2019).

\section{Conclusiones}

Como conclusión se destacan tres ideas principales fruto de las investigaciones y análisis llevados a cabo tanto durante la realización del artículo, como anteriormente en el trabajo de campo conjunto con los agentes implicados en el área de Villaverde:

La situación socio-económica del distrito sugiere la necesidad de planes de actuación estratégicos a medio y largo plazo que aseguren la mejora progresiva de las condiciones de quienes viven en la zona. Se evidencia que, a pesar de los incontestables avances en el conjunto de la ciudad de Madrid, y del aumento exponencial de la inversión en el ámbito inmobiliario desde 2012 en el conjunto de la Comunidad de Madrid, la situación estructural de vulnerabilidad se mantiene en el distrito, como el propio Ayuntamiento reconoce en la diversa documentación consultada.

Dada la situación actual de dificil acceso a la vivienda, con un desequilibrio claro entre ingresos y gastos destinados al pago de la hipoteca o el alquiler en el conjunto de la ciudad de Madrid, los distritos como Villaverde están absorviendo buena parte de la presión inmobiliaria procedente de áreas más céntricas. Se considera así que frente al interés inmobiliario creciente en la zona, sería recomendable la vertebración de un plan que implique nuevos usos compatibles para la enorme bolsa de suelo industrial vacante, fruto de los diversos procesos de deslocalización progresiva, que permita mantener espacios productivos adaptados a las nuevas tipologías industriales. En este sentido, el actual sistema de planeamiento, que limita las actividades compatibles, puede suponer una desventaja en el desarrollo de la zona a medio plazo, limitando su expansión a usos industriales circunstanciales y transitorios, relacionados con la logística, cuya repercusión en la mejora y el desarrollo del conjunto del distrito son cuestionables si no se encajan en un plan conjunto. Frente a ello, la conclusión a la que se 


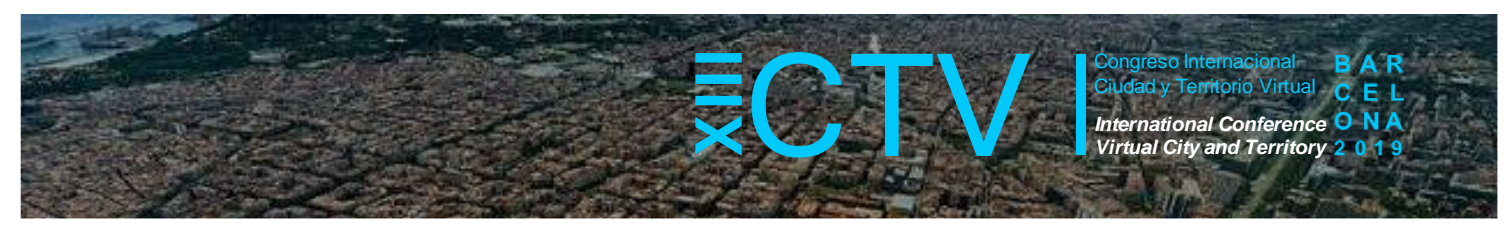

llega en este estudio es la idoneidad de desarrollar planes especiales de planeamiento que impliquen actividades compatibles mixtas en parcelas de carácter industrial vacante. De este modo, dada la evidente tendencia hacia actividades manufactureras y logísticas de poca afección, se pueden plantear ordenaciones innovadoras en las que distintos usos cohabiten frente a la segregación tradicional conforme al Plan General.

Finalmente, analizando la situación socio-demográfica del distrito, de demanda inmobiliaira en el mercado de alquiler en la zona, su emplazamiento respecto al conjunto de la red de transportes, y en linea con el interés vecinal, se concluye en la potencialidad de Villaverde como área de desarrollo residencial en alquiler para colectivos de jóvenes estudiantes, personas de edad avanzada y familias en riesgo de exclusión, que permitiría introducir nuevos perfiles sociales en el ámbito de forma controlada, adelantándose a procesos de gentrificación y favoreciendo la integración de estos perfiles en la vida del barrio.

Agradecimientos: A todos los colaboradores de Madrid Borde Sur, especialmente AA.VV. La Incolora, AA.VV. Colonia Marconi, AA.VV. Los Hogares y JMD. Villaverde.

Contribuciones de los autores: Ajuriaguerra M. ha desarrollado el apartado 1.1 así como la metodología y parte del punto 2, López Parejo A. ha desarrollado parte de los apartados 1 y 2 , Areco E. ha desarrollado parte del apartado 1 y el contenido gráfico. El punto 3 se ha desarrollado de forma conjunta.

Conflicto de Intereses: Los autores declaran que no hay conflicto de intereses.

\section{Bibliografía}

Agencia Tributaria. (2016). Estadística de los declarantes del IRPF de los mayores municipios por código postal. Recuperado de

https://www.agenciatributaria.es/AEAT/Contenidos_Comunes/La_Agencia_Tributaria/Estadistic as/Publicaciones/sites/irpfCodPostal/2016/jrubikf4f548f53ce61f391620583e2ecbb94f0a134360 d.html.

Ajuriaguerra, M.A, Braojos Bueno, L.I, y López Parejo, A. (2019). Aristráin Villaverde, el menguante legado industrial del desarrollismo frente a la especulación en el sur de Madrid.

Alfonso Sánchez, R. (mayo, 2017). Economía colaborativa: un nuevo mercado para la economía social. CIRIEC-España, revista de economía pública, social y cooperativa, (88) 7. Recuperado de https://doi.org/10.7203/CIRIEC-E.88.9255.

Ayuntamiento de Madrid. (2018). Distritos en cifras (Información de Barrios). Recuperado de https://www.madrid.es/portales/munimadrid/es/Inicio/El-Ayuntamiento/Estadistica/Distritos-encifras/Distritos-en-cifras-Informacion-de-Barrios-

/?vgnextfmt=default\&vgnextoid=0e9bcc2419cdd410VgnVCM2000000c205a0aRCRD\&vgnextch annel=27002d05cb71b310VgnVCM1000000b205a0aRCRD.

Ayuntamiento de Madrid, y Universidad Carlos III UC3 (2018) Metodología para la elaboración del índice de vulnerabilidad territorial de barrios y distritos de Madrid y ranking de vulnerabilidad (101)

Banco de España. (2019). Indicadores del mercado de la vivienda. Recuperado de https://www.bde.es/webbde/es/estadis/infoest/si_1_5.pdf 


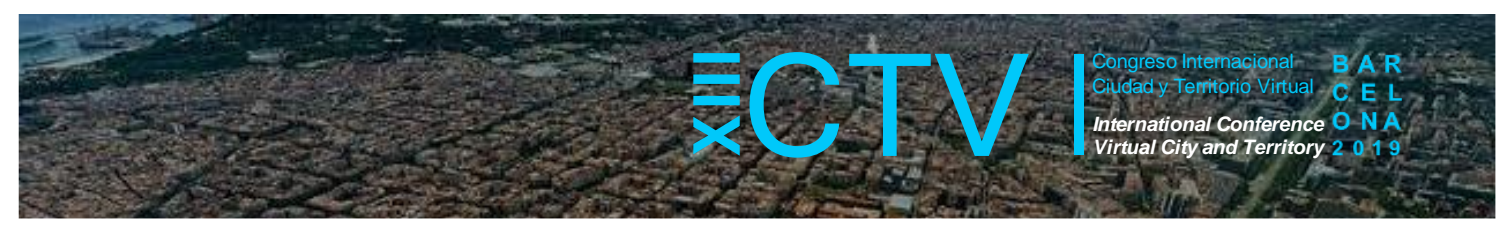

Bellod Redondo, J. F (2007). Crecimiento y especulación inmobiliaria en la economía española. Principios: estudios de economía política, (8), 59-84.

Colegio de Registradores de la Propiedad, Bienes Muebles y Mercantiles de España. (mayo, 2019). Estadística registral inmobiliaria. Recuperado de http://www.registradores.org/wpcontent/estadisticas/propiedad/eri/ERI_1T_2019.pdf

Corbi, M. (2019). \% de Renta Dedicada al Alquiler. Recuperado de Flourish. https://public.flourish.studio/visualisation/443570/

Dominguez Perez, M, y Leal Maldonado, J. (2008). Transformaciones Económicas y Segregación Social En Madrid. CIUDAD Y TERRITORIO Estudios Territoriales, XL (158). Recuperado de https://www.academia.edu/4412896/Transformaciones_econ\%C3\%B3micas_y_segregaci\%C3 \%B3n_social_en_Madrid

Fernández Gómez, Julio A. (2004). Buscando el pan del trabajo: sobre la industrializacion franquista y sus costes sociales, Villaverde (Madrid 1940-1965). 4.a ed. Madrid, España: Miño y Dávila.

García Pérez, E. (2014). Gentrificación en Madrid: de la burbuja a la crisis. Recuperado de https://scielo.conicyt.cl/scielo.php?pid=S0718-34022014000200005\&script=sci_arttext.

Hernández Aja, Agustín; Rodríguez Alonso, Raquel; Rodríguez Suárez, Iván; Gómez Jiménez, José Manuel; González García, Isabel; Córdoba Hernández, Rafael; Alguacil Gómez, Julio; Camacho Gutiérrez, Javier; Carmona Mateos, Fernando; Jaramillo Cáceres, Sergio. (2018) Barrios vulnerables de las grandes ciudades españolas. 1991 / 2001 / 2011. Madrid: Instituto Juan de Herrera (IJH) 73-103.

Hiernaux, D, y González, C. I. (septiembre, 2014). Turismo y gentrificación: pistas teóricas sobre una articulación. Revista de geografía Norte Grande, (58) 55-70. Recuperado de https://doi.org/10.4067/S0718-34022014000200004.

Instituto de Estadística, Comunidad de Madrid (2019). Instituto de Estadística, Comunidad de Madrid. Recuperado de http://www.madrid.org/iestadis/.

Lantigua, I. F. (5 de marzo, 2019). Los madrileños destinan casi la mitad del sueldo a pagar el alquiler. ELMUNDO. Recuperado de https://www.elmundo.es/madrid/2019/03/05/5c7d8ac2fdddff78178b45ab.html.

Ministerio de Industria. (2019). Informe ejecutado. Recuperado de Datalnvex http://datainvex.comercio.es/CabeceraPersonalizada. $a s p x$ ?id=1\&cambiarTipo=barras\&.

Muñoz Carrera, O. (2011). Gentrificación y reestructuración del espacio social en Madrid. Recuperado de Observatorio Metropolitano. http://www.observatoriometropolitano.org/wpcontent/uploads-observatorio/2011/03/GENTRIFICACI\%C3\%93N-Y-

REESTRUCTURACI\%C3\%93N-DEL-ESPACIO-SOCIAL-EN-MADRID.pdf.

Parra, I. D. (2014). La gentrificación, un regreso a la ciudad de la intervención urbanística, 20.

Ayuntamiento de Madrid (2015). Renta neta media de los hogares (Urban Audit) Ayuntamiento de Madrid. Recuperado de www.madrid.es: https://cutt.ly/oer44je.

Santiago Rodríguez, E (2007). Madrid "ciudad única" (II). La explosión urbana en la región madrileña y sus efectos colaterales. Urban, (13) 138-64. 